\title{
Criteria for Evaluating Research: The Unique Adequacy Requirement of Methods
}

\section{John Rooke \& Mike Kagioglou}

Published as: Rooke, J. \& Kagioglou, M. (2007) 'Criteria for evaluating research: the unique adequacy requirement of methods,' Construction Management and Economics, 25(9):979-987.

\section{Abstract}

The Unique Adequacy requirement of methods (UA) is proposed as a means of evaluating research in construction management. UA addresses the problems stemming from the significance of conscious action in constituting human organisation. These may be summarised as: first, that objectivity is a problematic concept in such studies; second, that the determination of meaning is their primary goal; and third, that formal procedures, whether as methods of research or explanation, have significant limitations. The UA requirement has two forms: the weak form demands that the researcher is competent in the research setting; the strong form, that research reports use only concepts originating within the research setting. The consequences of applying these criteria are explored with reference to recent research reports in construction management, including: a questionnaire survey of cultural difference; an exercise in grounded theorising; a case study of the implementation of a quality management initiative. It is concluded that the UA requirement is a viable tool for evaluating and 
guiding research. Emphasis is placed on the importance of maintaining a principled distinction between empirical research and theory building.

Keywords: Research Methods; Methodology; Culture; Grounded Theory; Total Quality Management

\section{Introduction}

The Unique Adequacy (UA) requirement of methods is proposed below as a means by which research in construction management (CM) may be evaluated and improved. To provide a background to this proposal, the methodological debate which took place in CM in the mid 1990's is briefly revisited. The problem of non-positivist standards for research is identified as an unresolved issue in this debate. The UA requirement is derived from the sociological discipline of ethnomethodology (Sharrock 2001; Francis \& Hester 2004; Ten Have 2004) within which it constitutes a central research policy (Garfinkel 2002; Rooke \& Seymour 2005). However, the intention here is not to recommend an ethnomethodological programme of enquiry, but to enrich the practice of construction management research. Nevertheless, some background to the origin of the UA requirement is provided as an aid to understanding its purpose and uses. The requirement is then specified in both its strong and weak forms. Finally, its application is illustrated with regard to three recent research reports in construction management. The UA requirement evaluates the products of research, reports and knowledge, rather than attempting to specify the methods employed to achieve them. It is shown here how this enables the UA criteria to be applied over a diverse range of research designs. 


\section{Methodological prescriptions in construction management}

This paper addresses a problem that was introduced to the pages of $C M E$ in the mid 1990's by Seymour \& Rooke (1995). It stems from a distinction between natural and social science posited on the observation that human beings, unlike the objects of physics and chemistry, are conscious beings who are capable of reporting on their own activities. Seymour \& Rooke point to three consequences of this for research that has such conscious report makers as its object, that : (1) objectivity is a problematic concept in such studies; (2) the determination of meaning is their primary goal; and (3) that formal procedures, whether as methods of research or explanation, have significant limitations.

There followed a critique of research practice aimed at what they termed the 'rationalist paradigm,' a dominant complex of ideas, including: (1) an assumed distinction between objectivity and subjectivity; (2) a reliance on causal explanation; and (3) a practice of causal model building which posits separate human and technical systems. Against this, an interpretative paradigm was posited, representing a diverse range of approaches which included (inter alia): Weber's verstehen, symbolic interactionism, ethnomethodology, learning organization and soft systems. Seymour, Crook \& Rooke (1997) assert:

$$
\begin{aligned}
& \text { "because the vast majority of our data consists of what managers tell us, the } \\
& \text { relationship between the manager and researcher is best characterized as one } \\
& \text { between an instructor and instructee.” (p118) }
\end{aligned}
$$

The proposal of competing paradigms, generated some consternation. Raftery, 
McGeorge \& Walters (1997) responded with a warning as to the divisive effects that inter-paradigm warfare might have on the community of construction management researchers. They proposed a multi-paradigm approach in which the two paradigms could be combined in a single approach to research. The warning may have had some effect in preventing debate from straying too far from ordinary standards of politeness, but their suggested approach was revealed to be problematic. It was pointed out that a paradigm is not so much as set of methods that may be mixed and matched with methods taken from comparable sets, but a methodology, concerned with the criteria for selecting methods and interpreting the findings they produce (Crook 1997; Root, Fellows \& Hancock 1997).

Runeson (1997), arguing from a positivist perspective, made a further contribution, pointing out that construction management is not a discipline in its own right, but a topic area which is subject to treatment by diverse disciplines. In addition, he drew attention to an important distinction between value neutral scientific research and practical (means ends oriented) management research. His chief concern was that interpretative ideas might undermine the rigorous application of scientific method. A chief intention of the current paper is to re-address this concern by proposing rules for the conduct of nonpositivist research in construction management.

A third critique of the interpretative position centred on Seymour, Rooke \& Crook's (1997) questioning of the role of theory. Harriss (1998) argued strongly for the necessity of theoretical formulations, equating them with forms of practical reasoning used by members of society in ordering their everyday affairs. In doing so, he opted for a view of theory that is practically oriented, in contrast to the disinterested positivist 
science advocated by Runeson. Wieder (1974) has documented how such home grown 'common sense' theories find their way into text books as putative 'scientific' theories, thus revealing how, in addition to informing research, theories are also the topics of research.

It is not simply that members of the construction industry have their own ideas about what they are doing. More fundamentally: these ideas are constitutive of their activities. Thus, if we want to understand a particular industry practice, we must look to the theories, ideas, or beliefs that underpin that practice. If we wish to make predictions about such practices, their incidence or development, an understanding of the concepts which constitute them is logically prior to any hypothetical proposal of a causal relationship.

Moreover, while formal research methods (such as, inter alia, the hypothetico-deductive method, the structured interview, or the controlled experiment) may have their place, the determination of meaning relies on the ordinary 'documentary method' of human interaction (Garfinkel 1984). That is to say, in researching an unfamiliar industry setting, the researcher learns about it in the same way that any other person would learn about it when entering it for the first time.

The problem then is this: what kind of standard can be adopted to evaluate research that takes into account this vital dimension of meaning? To be effective, such a standard must be capable of conferring factual status on items in the research report, differentiating them from inaccuracies on the one hand and (researcher/theorist's) value judgements on the other. 


\section{Origin of the UA requirement}

The UA requirement can be seen as a respecification of Schutz's (1962) postulate of adequacy. Schutz observed that scientific theories require objective terms in order to function. That is to say, for a theory to have logical consistency the terms that are used to construct it must have a consistent meaning on every occasion that they are used within it. While such consistency is achievable within a scientific community dedicated to the study of physical, non-conscious phenomena, a problem arises when the phenomena are themselves conscious theory-making beings. Sacks (1963) characterised this problem with his metaphor of the commentary machine: a machine whose activities are the object of scientific study, but which produces its own commentary on those activities. As Sacks observed, the problem is: what status is to be given to the machine's own commentary?

Schutz's solution was given in the form of three postulates: logical consistency; subjective interpretation; and adequacy. The postulate of logical consistency demands clarity of definition and compatibility with the rules of formal logic. This gives the model its objective validity. Strict logic, Schutz noted, "is one of the most important features" (1963, p43) distinguishing scientific from common sense thought. He argued that objectivity is achieved in practice by reconciling the subjective perceptions of different individuals. This is as true in natural science as in social science (Lynch 1991) and is summarised in Schutz's term 'inter-subjectivity'.

However, the strict control that a scientific community normally exercises over the meaning of terms is not possible in the study of meaning attributing communities. Garfinkel referred to the "unsatisfied programme” (1984, p. 4 passim) of attempting to 
substitute objective terms for those terms (known as indexicals) whose meaning varies according to the context of their use. However, he argued that the indexical qualities of terms are themselves orderly, thus suggesting both a new field of study and a possible way out of the dilemma.

The postulate of subjective interpretation asks,

"what model of an individual mind can be constructed and what typical contents must be attributed to it in order to explain the observed facts as the result of the activity of such a mind"? (Schutz 1963 p43)

An example of such a model of mind is the notion of the economic maximiser in economics. The creation of such a model makes it possible to refer actions or results of actions to the meaning they had for the actor. In this way, the meanings attributed by actors are built into the scientist's explanatory models. Garfinkel (1984) also questioned the utility of this postulate suggesting that, since such models can only contain those decision making rules that the theorist has built into them, they will inevitably have limitations in accounting for human behaviour. Thus, even models that have some predictive power may act as obstacles to new knowledge when used as guides to research.

Finally, the key difference between natural and social science was characterised by Schutz in terms of the 'postulate of adequacy'. This holds that any act referred to in a theoretical model must be understandable by the actor, and by those observing the act, in common sense terms. In this way, any alternative point of view held by the subject(s) of the research is taken into account in the formulation of a theoretical account. 
Garfinkel (1984) operationalised Schutz's postulate of adequacy as a radically empirical research programme. Here, the actor's common sense understanding, rather than being merely a check on abstract theorising, as in Schutz's formulation, takes centre stage. However, in contrast to subjectivist approaches, the inter-subjective and objective nature of “immortal ordinary society” (Garfinkel 2002) as produced through common sense understanding is emphasised. Indeed, the attainment of objectivity for particular purposes in particular settings becomes one focus for study.

For the purposes of giving such studies an objective status within the scholarly community concerned with undertaking them (Sacks 1963) the UA requirement (Garfinkel \& Weider 1992, Garfinkel 2002) may be employed. Stressing as it does the primacy of indigenous analytic methods in the understanding of research topics, UA may be regarded as a refined formulation of the postulate of adequacy. This formulation forgoes the building of theoretical models to attempt a more empirically accurate account of human activity. It has recently been recommended as a guide to research in diverse disciplines and subject areas (Crabtree 2004; Lindwall \& Lymer 2005; Rooke \& Seymour 2005).

Rooke (1997) has previously argued for the adoption of an ethnomethodological approach to research in which theorising, both lay and professional becomes an empirical focus. Such an approach has the dual advantage of incorporating the main thrust of the interpretative critique, whilst maintaining standards for research that are at least as rigorous as those of positivism. However, Rooke's proposal contains some important flaws and limitations. First, it is suggested that formal methods of investigation produce findings that are devoid of empirical validity. Though validity is a serious problem for 
survey research, while this is not the case for participant observers (Jorgensen 1989), the claim is exaggerated. Second, the critique of objectivity lacks subtlety. It is true that for ethnomethodology the social world cannot be observed from a privileged perspective, but it is important to note that observations may nonetheless have two significant characteristics that can be seen as objective. First, the objective reality of any organisational setting is achieved inter-subjectively by and for its members and is unquestionable for members of that setting. Second, these achieved organizational realities have consequences outside the setting. While this position is far removed from the ideal of objectivity espoused by the positivists, it is equally distant from the subjectivism feared by commentators such as Runeson and Harriss and seemingly adopted by some advocates of post-modernist approaches. Third, Rooke suggests that qualitative methods are comparatively time consuming and expensive. There are good reasons to suppose that this is not the case. The kind of armchair research suggested by Francis \& Hester (2004) in which experienced researchers and other industry members systematically analyse their own knowledge may well be more cost effective than the administration of surveys. On the other hand, rich qualitative data is far more flexible in its application than survey or experimental data and with sophisticated and flexible research design can be used to answer more than one question. Fourth, two ethnomethodological policies are recommended: ethnomethodological indifference and UA. While this follows common practice (Lynch 1999; Garfinkel 2002) it is arguable that the former is included in the latter (Rooke \& Seymour 2005). Thus, it is more economical to recommend the UA requirement in its weak and strong forms. Fifth, ethnomethodology has particular aims that derive from its nature as a sociological practice. While attention has been given to the hybridisation of disciplines, these 
attempts are still subject to debate (Button \& Dourish 1996, Crabtree 2004, Brown 2005, Rooke \& Seymour 2005). Rooke (1997) leaves the question of how the aims of ethnomethodological research are to be reconciled with those of construction management unasked, with the consequence that research aims may become confused. The adoption of the UA requirement as a stand-alone method for evaluating research avoids ambiguity on these matters, establishing that, while the evaluation criteria are borrowed from ethnomethodology, the aims of the research are those of construction management. As a consequence, as is suggested in the examples below, the UA criteria can be usefully applied to a much wider range of research than merely ethnomethodological studies.

\section{Specification of the UA requirement}

The UA requirement of methods does not prescribe specific methods for research. It consists of two related criteria: the weak and strong forms. In its weak form, the UA requirement demands that to analyse a construction industry setting adequately, we must know what any participant in that setting would ordinarily know about it. This knowledge, expressed as competence, is the kind referred to by Ryle (1963) as 'knowing how'; it consists in being able to perform relevant activities within that setting without censure from other members. The question of whether such an understanding has been achieved is a matter for the judgement of any other competent participant.

In this form the requirement is proposed as a criterion for adequate ethnography (Garfinkel \& Wieder 1974), the most certain method for acquiring such knowledge being 
participant observation. However, it is possible to usefully apply it to other forms of enquiry, such as interviews and questionnaires. Thus, for instance, a questionnaire designed by someone who had no direct knowledge of the activity under study is likely to contain irrelevant, misleading or meaningless questions, as demonstrated below.

Meeting the weak requirement is a researcher's problem. Any member of the setting (that is anyone having sufficient competence to operate in the setting without censure) is capable of delivering an account of that setting which meets the weak requirement. For a researcher encountering that setting for the first time, it is a matter of achieving this basic level of competence.

By contrast, the strong requirement concerns the reporting of research. It demands that the methods of analysis used to report on a setting should be derived from that setting. In effect, it stipulates the application of a policy of 'ethnomethodological indifference': a refusal to evaluate, describe or explain the activities that constitute the setting using criteria, concepts or theories that are not a part of that setting.

This criterion is possible because human organizational settings are constituted using methodological procedures that are sufficient to account for them. The methods that members of a setting use to make their meanings clear to other members of that setting, to create and maintain that setting, to make it work, are sufficient to the purpose of analysing that setting. Thus, producing a description of that setting is a matter of seeing how that setting is made to work by its members and presenting these methods in the report. Any other methods must involve some distortion of the phenomenon. However, as Lynch (1999) affirms, “indifference is not the same as a value-free or value-neutral posture” (p. 221) it is primarily intended to exclude only value judgements from outside 
the research context. Such non-indigenous judgements are more likely to be made when the nature of the value judgements that constitute the context of the research are not understood. Hence, it is necessary to achieve the weak requirement, if the strong requirement is to be achieved also.

While the weak requirement demands only a conscientious attitude from researchers, in that they are to employ ordinary common sense methods of enquiry to learn the research setting, the strong requirement calls for the exercise of a specific research practice, ethnomethodological indifference. It requires that researchers learn the skilful exercise of this practice (Lynch 1999).

\section{Applying the requirement to research reports}

\section{Cultural surveys}

A class of research report that fails to meet the weak UA requirement is the growing number of studies that rely upon questionnaire surveys to establish national cultural differences (e.g. Fisher \& Ranashinghe 2001; Tam, Fung \& Chan 2001; Phua \& Rowlinson 2004; Zhang \& Liu 2006). The use of formal survey methods to study culture is particularly problematic as culture is above all an interpretative process. The problem is most pronounced when widely divergent cultures are compared and the survey instruments used are designed from a single cultural perspective. Interpretative assumptions made in designing questionnaire surveys tend to pre-empt the results, leading to abstract findings with only a tenuous relationship to their empirical referents. 
Where the weak UA requirement is not met, meeting the strong requirement is effectively impossible. Phua \& Rowlinson (2004), for instance cite their main finding as being that, contrary to expectations, "Chinese senior managers are in fact less collectivist and less co-operative, at both intra- and inter-organizational level, compared to AngloSaxon senior managers” (p. 919). But to interpret their survey results in this way is to overlook the very cultural differences they set out to investigate. Thus, for instance, the first parameter in the instrument they use to measure collectivism asks for an evaluation of the statement: "You prefer to work with others in a group rather than working alone" (p. 924). This type of question may be adequate for assessing differences between individuals from similar cultural backgrounds, but it begs the question: is the difference between working in groups and working alone the same for Chinese and Anglo-Saxons? It is never the case that individuals are totally alone in any culture. It would seem reasonable to suppose that working alone in a collectivist culture involves more interaction with others than working alone in an individualist culture. Similarly, working groups are likely to be more tightly knit in collectivist than individualist cultures. The same kind of problem exists with each of the parameters in this instrument. For instance it is not clear whether group members 'doing what they want' should be taken to mean following their own interests (individualist) or finding their own ways to contribute to the welfare of the group (collectivist).

The instrument for assessing and comparing in-group and out-group co-operation is also flawed inasmuch as it assumes that all respondents will make similar value judgements as to the constitution of the in-group and out-group. However, as has long been recognised (Nakane 1970; Hayashi 1988) criteria for the attribution of in-group 
membership can differ across cultures.

How could such mistakes occur? Phua and Rowlinson themselves highlight one of the difficulties when they observe:

"it is important for researchers to exercise a certain level of selectivity when developing a formal research framework such that only conditions that are regarded as pertinent to the research are chosen from an infinite spectrum of other possible conditions.” (2004, p. 914)

Inevitably, such a selection will be made according to a particular cultural bias. The generic nature of this problem is perhaps best illustrated by considering the limitations of Hofstede's (2002) classic ten year study of culture in IBM. Notwithstanding the rigorous and painstaking work involved in this massive enterprise and the intuitively pleasing instrument that it rendered, Hofstede (1997) himself notes a major limitation: the instrument overlooks differences of temporal orientation and differential preference for the values of truth or virtue that distinguish between Western and Eastern cultures. Significantly, this additional dimension is made apparent in two ways: [1] through ethnographic work and [2] through comparison of Hofstede's Western designed survey with a Chinese designed survey. It could never be discovered through the application of Hofstede's questionnaire alone since, like any closed question instrument, this systematically excludes any data which might challenge the assumptions built into it. Thus, a closed question questionnaire that does not meet the UA requirement cannot itself repair this deficiency.

A further difficulty is constituted by the fact that those conditions which are selected for study comprise complex abstract concepts that are treated as simple variables. Thus, 
attitude to group-work, for instance, is not a single dimension, but a conglomerate of various judgements and behaviours carried out over time with reference to an evolving working environment. In order to answer Phua \& Rowlinson's research question in a manner that satisfies the UA requirement, it is necessary to adopt a method that will allow the elements of this conglomerate to be disaggregated in some way. One such method is Sacks' gloss (Garfinkel 2002) which, with regard to any particular research question, poses the further question: 'what work group, as their days work, and because they know it as their days work' (ibid, p182, emphasis in original) can answer this question? Thus, members of both Chinese and Anglo-Saxon work groups should be allowed to inform the researcher as to how they constitute themselves as groups.

\section{Grounded theory}

A type of research report which goes part way to satisfying the UA requirement is that which attempts to build grounded theory (e.g. Dainty, Bagilhole \& Neale 2000; Rooke, Seymour \& Fellows 2003; Dainty, Bryman, Price, Greasly, Soetanto \& King 2005). Dainty et al (2005, p242) used a "relatively loosely structured instrument” to investigate project affinity and are able to "reveal feelings about the project and the management of it and to determine the factors likely to encourage their commitment to the overall project objectives.” The study is particularly notable for its illustration of the process of affinity formation with illustrative quotations from project members which refer to particular activities. In allowing respondents to speak for themselves in this manner, they were able to capture not just the high level of commitment on one of their four case study projects, but the reasons for it and its practical outcomes. What is captured is not just an indicator, but a glimpse of a process in which project members understand and 
produce the setting in which they work. Thus, when members speak of their perception of the importance of the project, this is not an abstract concept, but a real feature of their work setting, a setting which they themselves are actively helping to produce.

Take Dainty et al's first piece of data (pp 242-243). For one member the importance of the project is said to make "good conversation points." Furthermore, it is represented in the project's house magazine which he can show to friends and family, as part of the process of telling them about the project. The finished building is envisaged as a continuing source of pride and interest, as return visits are anticipated. Thus, the respondent relates a social process during which feelings of pride are generated and maintained.

This piece of data can be seen to satisfy the weak UA requirement in the following ways:

1. We can see the methods by which this process is produced (conversing, reading, showing, telling, anticipating);

2. We are familiar with, and can be sure that the researcher is familiar with, these methods (we all know how to use them and what effects they may be expected to have).

Dainty et al illustrate the project affinity process using four such pieces of data. The first and second refer to methods of establishing the importance of the project: as having a place in medical history; as facilitating hoped for achievements; as directly relevant to the fate of one's close family. The second and third identify ways in which project affinity is demonstrated:

(i) working hard to make the project "go dead smooth” (p243); 
(ii) coming in earlier in the mornings;

(iii) making extra checks to ensure that there are no leaks.

Finally, in the fourth piece of data, a respondent illustrates additional considerations which lead to increased project affinity: the decency of the company; the challenge inherent in the work; and the feeling that good work is recognised and appreciated.

A note of caution is necessary. The data, illuminating as it is, is produced not in the process of acquiring and demonstrating project affinity, but in an interview process in which is a product of the research. Thus, the report as a whole is uniquely adequate to accounting for the interview process and not the project affinity process per se. It might be said to be adequate to the discussion, though not the practice of project affinity. On the one hand, the quotations themselves are uniquely adequate accounts and often constitute actual displays of project affinity. On the other, they have been generated and selected through an interview and analysis process which is obscure. Closer analysis of the interview process would remove this difficulty (Roulston 2001, Roulston, Baker \& Liljestrom 2001). Nevertheless, some limitations can be identified by closer inspection of the data. Thus, while the third piece of data specifies additional efforts the nature and effects of which may be estimated by the reader, the second piece of data constitutes a claim to be making additional effort without specifying its precise nature and effects. It is arguable that, as it stands, this report also goes some way to meeting the strong UA requirement, in basing its analysis on the understandings of project participants. However, there is an apparent contradiction between the intention to create grounded theory (Glaser \& Strauss 1967; Glaser 1992; Strauss \& Corbin 1998) and the strong requirement for ethnomethodological indifference. It is possible that such theory will 
develop in a way that mirrors the constitution of the setting, in which case the UA requirement can still be met. However, the more extra-contextual concepts are introduced, the greater the deviance from strong UA.

\section{The use of established theory}

A UA response to theoretical formulations is to ask how such theories play out when employed in practice. However, this is not a crypto-positivist stance which requires the statement of a formal method and a set of results, but one which recognises the application of theoretical formulations as a process in itself worthy of study. Stewart \& Spencer (2006) report on a case study of a Process Improvement Project (PIP) seeking to reduce delays to the construction of raised platform beams. The research had two objectives: to [1] “describe the application of the six-sigma method on a construction project” (2006, p343); and [2] to evaluate its effectiveness. The method adopted consisted primarily of recording and reporting "decisions made and their outcomes” (ibid.) in the process of implementing a six-sigma PIP, using the stages defined in sixsigma theory: design, measure, analyse, improve and control. In using a research method that is given by the logic of the improvement method they are researching, Stewart and Spencer make an important move towards meeting the strong UA requirement.

As implementation developed, shortcomings in the construction process were defined, their causes investigated and identified and solutions developed, implemented and monitored. The relationship between the formal theory and the contingency of actual on-site production is illustrated, for instance, when a second PIP is instituted to address problems of co-ordination that emerged as major obstacles to the primary objective. 
Specific details are offered, such as decision, objective, measures, recording procedure, application, and outcome. As Stewart \& Spencer observe, these findings should provide a solid basis for further work by both academics and practitioners. If the report does in fact find use among practitioners, this would stand as strong evidence of its unique adequacy (Rooke \& Seymour 2005).

However, as it stands, the paper does not fully meet the test of the strong criterion. This is due to the way that disagreements within the project team are dealt with, a problem arising from a subsidiary methodology in which project participants were interviewed in order to evaluate the PIP. Thus, project participants' view that "six-sigma mainly improved efficiency but not quality" is dismissed as “a common misconception about the concept of 'quality' and its relationship to the whole procurement process” (Stewart \& Spencer 2005, p346). Here, a concept derived from the theory of quality management is used to evaluate the participants' own evaluation and theorising. A better approach would be to note the different meanings of quality held by participants and interviewers and to ask how these different meanings work in the reasoning of each party. This is not to argue that Stewart and Spencer are wrong in their theoretical formulation, only to point out the inconsistency of introducing such formulations ad hoc into a research report which at other times takes the theoretical formulations of project members as data. Like other features of the theory of quality management, the viability of the technical definition of quality must be vindicated in practice. Furthermore, even when such a theoretical definition is proved useful, this does not provide warrant for dismissing other uses of a term as incorrect. Nor is this merely a matter of methodological nicety, a thorough understanding of industry managers' reasoning processes may prove important 
for effective implementation. As it is, the reader is left uninformed about the nature and extent of informal (theoretically unaccounted for) reasoning that underpinned the process they describe.

\section{Conclusion}

This paper recommends the UA requirement as a candidate solution to the problem of what constitute effective criteria for the evaluation of research reports in which the perceptions of research subjects are an important part of the research topic. It does so by setting out the rationale behind the UA requirement and demonstrating its viability over a range of research strategies. The review of research reports above is intended to illustrate how the criteria may be applied. The paper does not attempt to review other possible solutions to this problem, or to comment on their viability.

Thus, it has been shown how the application of the UA requirement highlights problems arising from the administration of a culture survey questionnaire and indicates that closed ended questions are only appropriate for the investigation of already closely defined issues. Cultural comparisons which do not meet the weak UA requirement for one of the compared cultures run the risk of overlooking important features of that culture.

Similarly, questionnaires that are not designed to the strong requirement, that is to say the design does not arise out of the logic of the cultural settings under investigation, will fail to reflect those features in the data.

Through the examination of a grounded study, it has been shown the UA requirement provides criteria for specifying definitional evidence. 
Finally, though the UA requirement demands that reports be descriptive and rejects theoretical re-interpretation of the data, it has been shown that it can be used to evaluate a report of theoretically driven action research. Thus, the UA insistence on the importance of mutual understanding between researchers and other participants in the setting enables a distinction to be drawn between theory which has been accepted in the setting and that which remains alien to it.

The value of the strong UA requirement is that it requires the maintenance of a sharp distinction between research and other activities, including theorising and improvement initiatives. This facilitates the delivery of research reports that can be relied upon as guides to the setting that is being studied. Thus, while theory and improvement are both featured in the Stewart \& Spencer (2006) paper, applying the UA requirement allows us to see that, for the most part, these are reported as features of the setting. It also allows us to identify where the transition occurs between the reporting of research findings and a didactic presentation of quality management theory which stands in critical relation to the indigenous theoretical understanding of project participants.

In relation to grounded theorising, the situation is more complex. As can be seen above, the Dainty et al (2005) study goes a long way towards conforming to the UA requirement. Notwithstanding problems over the use of interview data, they seemingly depart from it in intention, rather than substance. Indeed, if theory is to consist entirely in accounting for the setting in terms of participants understandings, then grounded theory can conform completely to the UA requirement. However, the UA requirement alerts us to the danger that in the absence of an explicated interview process, concealed theoretical imports may exist in such reporting. 
Grateful thanks is extended to the anonymous referees whose extensive comments have helped greatly in the production of this paper.

Word count: 5469

\section{References}

Brown, B. (2005) 'Remarks on the foundations of computer science,' http://www.dcs.gla.ac.uk/ barry/papers/foundations.pdf (accessed 12/12/06).

Button, G. and Dourish, P. (1996) 'Technomethodology: Paradoxes and Possibilities,' in Proceedings of the ACM Conference on Human Factors in Computing Systems CHI'96 (Vancouver, BC), 19-26. New York: ACM.

Crabtree, A. (2004) 'Taking technomethodology seriously,' in European Journal of Information Systems, 13:195-209.

Crook, D. J. (1997) 'Empirical enquiry or metaphysics? Respecifying the methodological debate', Journal of Construction Procurement, 3(2):56-71.

Dainty, A. R. J., Bagilhole, B. M. \& Neale, R. H. (2000) 'A Grounded Theory of Women's Career Under-Achievement in Large UK Construction Companies', in Construction Management and Economics, 18(2):239-250.

Dainty, A. R. J., Bryman, A., Price, A. D. F., Greasley, K., Soentanto, R. \& King, N. (2005) 'Project affinity: the role of emotional attachment in construction projects,' in Construction Management and Economics 23(3):241-244.

Fisher, T. F. \& Ranasinghe, M. (2001) 'Culture and Foreign Companies Choice of Entry Mode: The Case of the Singapore Building and Construction Industry' in Construction Management and Economics, 19(4):343-353.

Francis, D. \& Hester, S. (2004) An Invitation to Ethnomethodology; Language, Society and Interaction, Sage, London.

Garfinkel, H. (1984) Studies in Ethnomethodology, Polity Press, Cambridge.

Garfinkel, H. (2002) Ethnomethodology's Program: Working out Durkheim's Aphorism, Rowman \& Littleford, Lanham. 
Garfinkel, H. \& Wieder, D. L. (1992) 'Two Incommensurable, Asymmetrically Alternate Technologies of Social Analysis', in G. Watson \& R. M. Seiler (eds.), Text in Context, Sage, London, pp. 175-206.

Glaser, B. G. (1992) Basics of Grounded Theory Analysis: Emergence v. Forcing, Sociology Press, Mill Valley, CA.

Glaser, B. G. \& Strauss, A. L. (1967) The Discovery of Grounded Theory; Strategies for Qualitative Research, Weidenfeld \& Nicholson, London.

Harriss, C. (1998) 'Why research without theory is not research: a reply to Seymour, Crook and Rooke,' in Construction Management and Economics, 16(1):113-116.

Hayashi, S. (1988) Culture and Management in Japan, (tr. F. Baldwin) University of Tokyo Press.

Hofstede, G. (1997) Culture and Organization: The Software of the Mind, McGraw Hill, London.

Hofstede, G. (2002) Culture's Consequences: Comparing Values, Behaviours, Institutions and Organizations Across Nations, ( $2^{\text {nd }}$ Edition) Sage, London.

Jorgensen, D. L. (1989) Participant Observation: A method for human studies, Sage, London.

Lindwall, O. \& Lymer, G. (2005) 'Vulgar competence, ethnomethodological indifference and curricular design,' in Proceedings of the 2005 Conference on Computer Support for Collaborative Learning: The Next 10 Years!, T. Koschmann, D. D. Suthers \& T.-W. Chan (Eds.) $30^{\text {th }}$ May-4 ${ }^{\text {th }}$ June, Taipei, Taiwan. ISBN:0-8058-5782-6

Lynch, M. (1991) 'Method: measurement - ordinary and scientific measurement as ethnomethodological phenomena,' in G. Button (Ed.) Ethnomethodology and the Human Sciences, Cambridge University Press.

Lynch, M (1999) 'Silence in context: ethnomethodology and social theory,' in Human Studies 22:211-233.

Nakane, C. (1970) Japanese Society, University of California Press, Berkeley.

Phua, F. T. \& Rowlinson, S. (2004) 'Operationalizing culture in construction management research: a social identity perspective in the Hong Kong context,' in Construction Management and Economics 22(9)913-925.

Raftery, J., McGeorge, D. \& Walters, M. (1997) 'Breaking up methodological monopolies: a multi paradigm approach to construction management research,' Construction Management \& Economics, 15(3)291-297.

Rooke, J. (1997) 'Developing a More Empirical Approach to Culture, Attitude and Motivation in Construction Management Research: A critique and a proposal,' in Journal of Construction Procurement, 3(2):45-55

Rooke, J. \& Clark, L. (2005) 'Learning, knowledge and authority on site: a case study of safety practice’, Building Research and Information, 33(6):561-570.

Rooke, J. \& Seymour, D. (2005) 'Studies of Work: Achieving Hybrid Disciplines in IT Design and Management Studies’, Human Studies 28(2):205-221. 
Rooke, J., Seymour, D. \& Fellows, R. (2003) 'The Claims Culture; A Taxonomy of Industry Attitudes', in Construction Management and Economics, 21(2):167-174.

Rooke, J., Seymour, D. \& Fellows, R. (2004) 'Planning for Claims; An Ethnography of Industry Culture’, in Construction Management and Economics, 22(6):655-662.

Root, D., Fellows, R. \& Hancock, M. (1997) 'Qualitative versus quantitative or positivism and interactionism - the superficiality of the current methodological debate', Journal of Construction Procurement, 3(2):34-44.

Roulston, K. (2001) 'Data analysis and "theorizing as ideology,"' Qualitative Research 1:279-302

Roulston, K., Baker, C. D. \& Liljestrom, A. (2001) 'Analyzing the researcher's work in generating data: the case of complaints,' Qualitative Inquiry 7:745-72

Runeson, G. (1997) 'The role of theory in construction management research: comment,' Construction Management \& Economics, 15(3):299-302.

Ryle, G. (1963) The Concept of Mind, Penguin, Harmondsworth.

Sacks, H. (1963) 'Sociological Description,' in Berkeley Journal of Sociology, 8:1-16.

Schutz, A. (1962) The Problem of Social Reality (Collected Papers, Volume 1) M. Natanson (Ed.) Marinus Nijhoff, The Hague.

Seymour, D., Crook, D. \& Rooke, J. (1997) 'The Role of Theory in Construction Management: A Call for Debate,' Construction Management and Economics, 15(1):117-119.

Seymour, D., Crook, D. \& Rooke, J. (1998) 'The Role of Theory in Construction Management: A reply to Runeson', Construction Management and Economics, 16(1):109-112.

Seymour, D. \& Rooke, J. (1995) 'The culture of the industry and culture of research', in Construction Management and Economics, 13(6):511-523.

Sharrock, W. W. (2001) 'Fundamentals of Ethnomethodology' in G. Ritzer \& B. Smart (Eds.) Handbook of Social Theory, Sage, London.

Stewart, R. A. \& Spencer, C. A. (2006) 'Six-sigma as a strategy for process improvement on construction projects: a case study,' in Construction Management and Economics 24(4):339-348.

Strauss, A. L. \& Corbin, J. (1998) Basics of Qualitative Research: Procedures and Techniques for Developing Grounded Theory (second edition) Sage, London.

Tam, C. M., Fung, I. W. H. \& Chan, A. P. C. (2001) 'Study of Attitude Changes in People After the Implementation of a New Safety Management System: The Supervision Plan', in Construction Management and Economics, 19(4):393-403.

Ten Have, P. (2004) Understanding Qualitative Research and Ethnomethodology, Sage, London.

Wieder, D. L. (1974) Language and Social Reality, Mouton, The Hague.

Zhang, S. B. \& Liu, A. M. M. (2006) 'Organizational culture profiles of construction 
Rooke \& Kagioglou 2007: Criteria for Evaluating Research

enterprises in China,' in Construction Management and Economics, 24(8):817-828. 